\title{
Sharing your work by self-archiving: encouragement from the Journal of the Medical Library Association
}

Abigail Goben; Katherine G. Akers

See end of article for authors' affiliations.

Self-archiving offers opportunities for authors to more broadly disseminate their work-both in pre-print form before its submission to a journal and in post-print form after its acceptance and publication in a journal. This editorial provides authors with guidance in navigating the rapidly changing options for self-archiving and affirms that the Journal of the Medical Library Association encourages authors to self-archive their work to boost its reach and impact.

As scholarly publishing continues to evolve, authors now have opportunities to openly share their manuscripts online to receive informal feedback from colleagues before submitting them to peerreviewed journals and to enhance their dissemination after journal acceptance. Although the Journal of the Medical Library Association (JMLA) has embraced its open access status for nearly twenty years [1,2], the JMLA team also recognizes that authors have other avenues through which to share their scholarly work and we encourage authors to ask the community for feedback on their manuscripts prior to their submission.

Self-archiving by sharing online pre- or postprint versions of manuscripts offers opportunities to engage in early conversations about manuscripts, to solicit critical feedback before their submission to journals, and to improve their accessibility to readers [3, 4]. In addition to facilitating scholarly discourse and potentially improving the strength of their manuscripts, self-archiving one's work allows librarians and information professionals to gain firsthand knowledge of the intricacies of scholarly communication through direct participation in emerging practices.

Engaging in self-archiving can introduce authors to unfamiliar jargon and a multitude of options that must be carefully considered in order to make informed decisions regarding which version of their manuscripts to share, when and where to share their manuscripts, and how to link their manuscripts to the publisher's versions of record [5]. This editorial provides a brief guide to self-archiving for health sciences librarians and information professionals and emphasizes JMLA's supportive stance on self-archiving.

\section{TIPS FOR SELF-ARCHIVING}

\section{Selecting which version to share}

When self-archiving, it is important to choose which version of the manuscript to share and when to share it during the writing and publishing process (Figure 1). Most journals have policies regarding whether, when, and where authors can post various versions, though these can also be negotiated by authors using the Scholarly Publishing and Academic Resources Coalition (SPARC) author addendum [6] or alternates.

- Pre-print: A pre-print is a version of a manuscript before it is submitted to a journal [7]. Sharing a pre-print can be a good way to solicit feedback from readers before formal peer review. However, some journals consider a preprint a form of prior publication and may, thus, be unwilling to consider the manuscript for publication. It is important to check the policies of target journals before publicly sharing a preprint, and it is good practice to state in the journal submission cover letter whether a preprint of the manuscript has been made publicly available. 
Figure 1 Versions of a manuscript that can be self-archived at different stages of the writing and publishing process

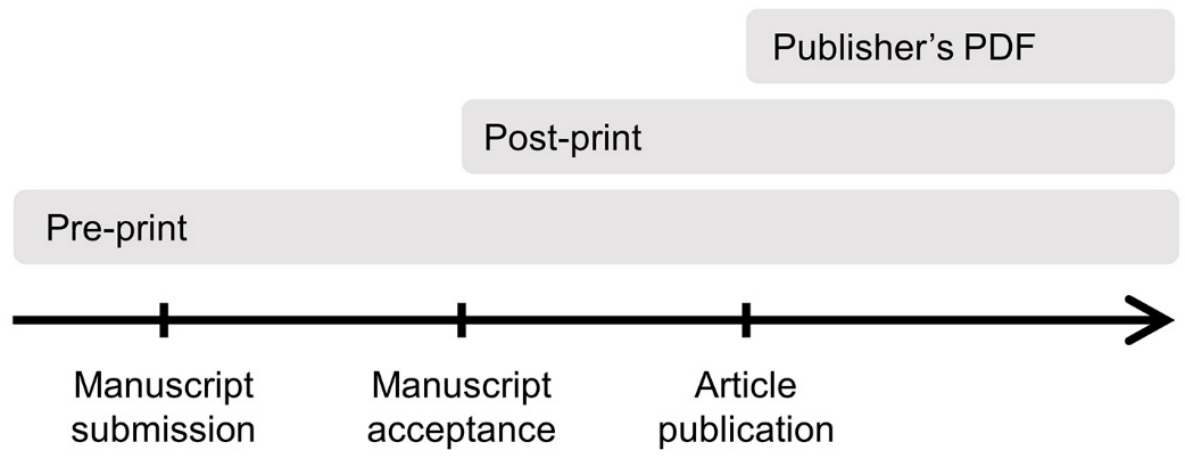

- Post-print: A post-print is the final, accepted version of a manuscript before it is typeset by the journal for publication [7]. It incorporates all revisions made during the peer and/or editorial review process. In addition to authors sharing a post-print, journals may release the post-print version of a manuscript before its formal publication; in PubMed, these appear with the designation "Epub ahead of print."

- Publisher's PDF: A publisher's portable document format (PDF) is a professionally copyedited, professionally typeset, and formally published version of an article. This seems to be the least common version for self-archiving, although the proportion of journals that explicitly allow self-archiving of the publisher PDF is unknown. An example of this policy is from the Journal of Dental Education, which requires archiving only of the publisher's PDF without embargo [8].

\section{Identifying journal self-archiving policies}

When self-archiving, it is essential to identify and understand the policies of journals to which one plans to or has already submitted a manuscript. To help accomplish this, the SHERPA/RoMEO resource aggregates the self-archiving and copyright policies of more than 22,000 journals. Searching SHERPA/RoMEO for a specific journal title yields information such as whether the journal allows selfarchiving of pre-prints, post-prints, and publisher's PDFs; where these manuscript versions can be posted; whether their release should be embargoed; and how they should be linked to the final publisher's version of record. To confirm the information found in SHERPA/RoMEO, authors should also consult the websites of their target journals.

\section{Selecting a location for self-archiving}

Authors have an increasing wealth of locations to self-archive their manuscripts.

- Disciplinary repositories: Two repositories in the field of library and information science (LIS) currently exist: LIS Scholarship Archive (LISSA) and e-LIS. LISSA is hosted on the Open Science Framework (OSF) and allows a variety of deposit types, including manuscripts, posters, data sets, and code. e-LIS is hosted by the Library System of the University of Naples Federico II and primarily serves as a repository of manuscript pre-prints, post-prints, and technical papers. Neither repository charges a deposit fee. Although PubMed Central (PMC) currently serves as the largest disciplinary repository for biomedical journal articles, including those in health sciences librarianship and information science journals, it strictly houses accepted versions of manuscripts (postprints or publishers' PDFs) that are published in PMC-participating journals (including JMLA) or supported by National Institutes of Health funding.

- Institutional repositories: Many academic libraries have an institutional repository (IR) that aggregates and preserves the scholarly output of their institutions and facilitates author compliance with open or public access requirements. IRs predominantly house manuscripts, although they are increasingly 
being refactored or expanded to accept data, code, and other research materials. There is usually no charge for deposit in IRs, and the institution supports long-term preservation of the deposited materials.

- General repositories: General repositories, such as figshare and OSF, store and provide access to manuscripts and other research materials regardless of discipline or author institutional affiliation. General repositories vary in whether they are free or charge a deposit fee, and not all guarantee preservation of their contents.

- Academic social networking sites: Various forprofit websites, including ResearchGate and Academia.edu, aim to serve as general social networks in the academic arena. These websites encourage authors to post copies of their manuscripts for easy access and reuse by peers. Authors should understand the copyright agreements that they sign with their articles' publishers and the restrictions therein, as many journals explicitly do not allow posting of any manuscript version on for-profit websites. Additional concerns can arise regarding lack of preservation.

- Personal websites: Authors can post manuscripts or publishers' PDFs on their personal, research team, or departmental websites. This is a free option that allows authors to aggregate their works in their own web space, but it puts the obligation of hosting and managing the website directly on the author and can come at a cost to manuscript discoverability.

\section{Including the correct citation}

If authors opt to publicly share a pre-print or postprint before or after formal publication of their articles, it is best practice to provide a citation and/or link to the publisher's version of record with the self-archived manuscript. Some journals provide specific instructions for what type of information to include about the manuscript. In general, before the article is published, the citation should be approximated to resemble the anticipated final citation of the published article, replacing the year of publication and volume, issue, and page numbers with "in press," "publication pending," or "article accepted [date]." After the article is published, the self-archived manuscript should be updated with a final complete citation paired with a statement pointing readers to the publisher's version as the official version of record.

This process can be complicated if the repository housing the self-archived manuscript assigns digital object identifiers (DOIs), as ideally each scholarly object should have only one DOI. Authors may be able to request the temporary suppression of this field in a repository and update the record with the publisher-assigned DOI upon publication. If not, the pre-print or post-print will have one DOI, and the publisher's final version of record will have another DOI, and authors need to track both DOIs to assess their work's impact.

\section{Setting an embargo}

Some journals may request that authors wait until the article has been formally published before making their post-print publicly available. Accordingly, many repositories permit authors to set an embargo period during deposit that will automatically release the manuscript file on the appropriate date. This embargo allows the publisher's version of record to be the first discoverable version and may help prevent DOI duplication issues. Other journals, such as subscription-based journals, require that authors do not publicly share their post-print until one to three years after article publication. These journals argue this delay preserves the value of the journal, but the delay could ultimately decrease article readership and impact. Making a pre-print available before manuscript submission, if allowed by the journal, could serve to preempt this requirement.

\section{THE JOURNAL OF THE MEDICAL LIBRARY ASSOCIATION'S SUPPORTIVE STANCE ON SELF- ARCHIVING}

JMLA fully embraces the freedom of authors to share their work as widely as they desire to meet their own objectives - whether to obtain presubmission feedback, increase their readership, enhance the potential impact of their work, achieve professional recognition, or support the principles of research transparency and open science.

If you publish in JMLA, you retain copyright and grant our publisher the right to publish your work under a Creative Commons Attribution (CCBY) 4.0 license. You are permitted and encouraged to post a pre-print of your manuscript anywhere 
you choose. If your manuscript is accepted by and published in JMLA, we ask that you update your posted pre-print or post-print with the publisher's assigned DOI, which can be requested from the JMLA editor after acceptance, and a link to the online abstract for the final published article on the JMLA website. No embargoes are requested or required. You are also allowed to post the publisher's PDF anywhere you choose after publication of your article. These policies are described in greater detail on the Author Guidelines and Editorial Policies pages of the JMLA website and are shown in SHERPA/ RoMEO's entry for JMLA.

Health sciences librarians and information professionals who engage in scholarly publishing have the opportunity to explore, understand, and influence the availability of their own work and that of the health care professionals, researchers, and students they support. By highlighting the value of self-archiving, we emphasize JMLA's dedication to open access with the ultimate goal of amplifying our authors' voices and increasing the likelihood that their work will influence the profession's

knowledgebase and practice.

\section{REFERENCES}

1. Plutchak TS. What we don't know [editorial]. Bull Med Libr Assoc. 2001 Jan;89(1):77-8.

2. Plutchak TS. So long (and thanks for all the fish) [editorial]. J Med Libr Assoc. 2006 Apr;94(2):103-5.

3. Shuai X, Pepe A, Bollen J. How the scientific community reacts to newly submitted preprints: article downloads, Twitter mentions, and citations. PLOS ONE. 2012 Nov 1;7(11):e47523.

4. Berg JM, Bhalla N, Bourne PE, Chalfie M, Drubin DG, Fraser JS, Greider CW, Hendricks M, Jones C, Kiley R, King S, Kirschner MW, Krumholz HM, Lehmann R, Leptin M, Pulverer B, Rosenzweig B, Spiro JE, Stebbins M, Strasser C, Swaminathan S, Turner P, Vale RD, VijayRaghavan K, Wolberger C. Preprints for the life sciences. Science. 2016 May 20;352(6288):899-901.

5. Kaspar WA. Approaching a new year-and a new look for the journal. Coll Res Libr. 2018 Nov;79(7):860-2.
6. SPARC. Author rights: using the SPARC author addendum [Internet]. SPARC [cited 13 Oct 2019].

$<$ https://sparcopen.org/our-work/authorrights/brochure-html/>.

7. SHERPA/RoMEO. Definitions and terms: pre-print and post-print [Internet]. SHERPA/ RoMEO [cited 13 Oct 2019]. <http:// www.sherpa.ac.uk/romeoinfo.html\#prepostprints>.

8. Journal of Dental Education. Information for authors [Internet]. American Dental Education Association [cited 13 Oct 2019]. <http:/ / www.jdentaled.org/authorinfo>.

\section{AUTHORS' AFFILIATIONS}

Abigail Goben, agoben@uic.edu, http://orcid.org/0000-0002-65203648 , Library of the Health Sciences, University of Illinois at Chicago, Chicago, IL

Katherine G. Akers, JMLA@journals.pitt.edu, https://orcid.org/00000002-4578-6575, Editor-in-Chief, Journal of the Medical Library Association

Received October 2019; accepted October 2019

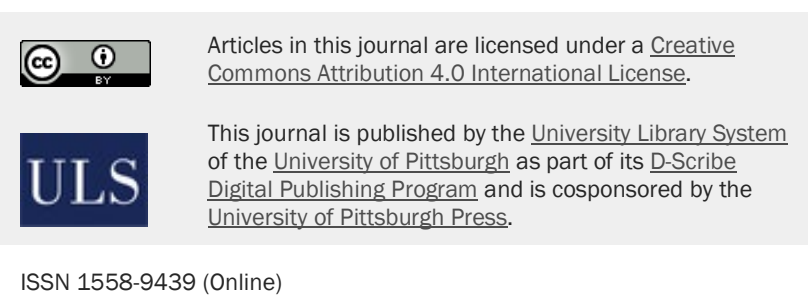

